\title{
Relações entre experiências pessoais e uma educação física sensível à diversidade cultural
}

\author{
Relationships between personal experiences and physical education \\ sensitive to cultural diversity
}

Relaciones entre experiencias personales y educación física sensibles a la diversidad cultural

\author{
Alexandre VASCONCElos MAZzoni ${ }^{1}$; MARCos Garcia NeIra ${ }^{2}$ \\ Universidade de São Paulo, USP, SÃo Paulo-SP, Brasil
}

\begin{abstract}
RESUMO
Realizou-se uma pesquisa com o objetivo de conhecer quais elementos possam ter contribuído para a constituição de uma docência da Educação Física atenta à diversidade cultural. Como procedimento metodológico, optou-se pela pesquisa pedagógica qualitativa. O material resultante da realização de entrevistas semiestruturadas foi confrontado com a teorização cultural. Partindo da análise das concepções de professores da rede pública, que colocam em ação o currículo cultural da Educação Física, inferiram-se as possíveis relações entre a experiência pessoal, o olhar para a contemporaneidade e a atuação pedagógica. Podemos inferir que os elementos que contribuíram para a constituição de uma docência da Educação Física atenta à diversidade cultural podem ter sido gerados por uma trajetória de vida marcada pelo enfrentamento de situações socialmente adversas.
\end{abstract}

Palavras-chave: Educação Física. Cultura. Currículo. Diversidade Cultural.

\begin{abstract}
Research was performed aiming to know which are the elements that must have contributed to build a Physical Education teaching practice that is concerned with the cultural diversity. As to the methodology, the pedagogical qualitative research. The material obtained from the semi-structured interviews was compared to the cultural theories. From the analysis of the conceptions of the teachers of the Public Schools, who put into action the cultural syllabus of the Physical Education teaching, were derived the possible relationships among the personal experience, the regard to the contemporaneity and the pedagogical practice. From the many analysis we could derive which are the elements that contributed to creating a teaching practice in Physical Education, which are concerned with the cultural diversity, and may have been generated by a life trajectory marked by socially difficult situations.
\end{abstract}

Keywords: Physical Education. Culture. Curriculum. Cultural Diversity.

\section{RESUMEN}

La investigación se realizó con el objetivo de conocer cuáles son los elementos que deben haber contribuido para construir una práctica docente de Educación Física que se preocupa por la diversidad cultural. En cuanto a la metodología, se adoptó la investigación cualitativa pedagógica. El material obtenido de las entrevistas semiestructuradas se comparó con las teorías culturales. A partir del análisis de las concepciones de los docentes de las escuelas públicas que pusieron en práctica el currículo cultural de la Educación Física, se derivaron las posibles relaciones entre la experiencia personal, el respeto a la contemporaneidad y la práctica pedagógica. De los muchos análisis que pudimos deducir cuáles son los elementos que contribuyeron a la creación de una práctica docente en Educación Física, que se preocupan por la diversidad cultural y que pueden haber sido generadas por una trayectoria vital marcada por situaciones socialmente difíciles.

Palabras clave: Educación Física. Cultura. Currículum. Diversidad Cultural.

1 Membro do Grupo de Pesquisas em Educação Física Escolar da USP. E-mail: mazzoni@centrodetreinamentokungfu.com.br

${ }^{2}$ Professor Titular da Faculdade de Educação da USP. E-mail: mgneira@usp.br 


\section{INTRODUÇÃO}

$\mathrm{O}$ atual momento de transformações sociais, políticas, econômicas e culturais somadas ao advento da globalização, tem gerado uma série de impactos $\mathrm{e}$ deslocamentos nos diversos espaços sociais e nos seus sujeitos. O fenômeno da globalização trouxe avanços para a dinâmica social, porém, também desencadeou vários problemas. Seguindo a lógica e as diretrizes capitalistas, foi ampliado o abismo entre a riqueza e a pobreza, intensificou-se a diversidade social, consolidou-se as riquezas nas mãos de poucos, concentrou-se a produção, estimulou-se o consumo em larga escala, acentuou-se as divergências culturais e avivou-se a pluralidade de identidades. A globalização também propagou modos de pensar e agir e trouxe uma nova configuração à sociedade baseada em condutas e discursos que possibilitaram novas demandas e novos olhares.

A globalização envolveu uma extraordinária transformação, determinando que as velhas estruturas dos Estados e das comunidades nacionais entrassem em colapso e cedessem lugar a uma crescente hibridização da vida e suas relações. O fenômeno da globalização determinou uma interação entre fatores econômicos e culturais, causando mudanças nos padrões de produção e consumo, os quais produzem identidades novas a todo momento. O desenvolvimento global do sistema capitalista não é, obviamente, novo, mas o que caracteriza sua fase mais recente é a convergência de culturas e estilos de vida nas sociedades, que, ao redor do mundo, são expostas ao seu impacto.

Diante de tantas turbulências e transformações, compreendemos que as velhas identidades, que por tanto tempo estabilizaram o mundo social, hoje, estão em declínio. Novas identidades estão surgindo, assim como novos marcadores sociais, novas responsabilidades, novas concepções que deixam o sujeito pós-moderno fragmentado, descentrado e deslocado (HALL, 2005). A "crise de identidade" faz parte de um processo mais amplo de mudanças, que está deslocando as estruturas e os processos centrais das sociedades modernas e abalando os quadros de referência que davam aos sujeitos uma ancoragem estável no mundo social.

Um dos locais sociais que mais sofreu com a nova configuração foi a escola. Impactada por ações e modos de pensar atrelados ao consumo, à produção e ao desenvolvimento econômico, a escola acabou por acatar diretrizes que pressionam e determinam o percurso curricular na busca por resultados que ao longo do tempo visam atender aos objetivos de mercado sem preocupar-se com seus sujeitos.

Sendo uma instituição cuja função transcende a preparação para o trabalho, a escola não pode restringir-se apenas a promover sujeitos aptos a mover a engrenagem mercantil do sistema capitalista. Simplesmente formar consumidores e produtores de bens materiais inviabiliza a função social de formação para a cidadania, tomando como base a democracia, o combate à desigualdade e a transformação social.

As experiências diárias mostram como a sociedade está conturbada com perseguições, marginalizações, preconceitos, violências, pobrezas, excesso (e falta) de trabalho e muitos outros fatores que pressionam os sujeitos da educação. Para uma sociedade tornar-se democrática se faz necessária uma escolarização que contribua para a formação cidadã e que facilite o entendimento das contradições que marcam a contemporaneidade.

O entendimento das situações sociais, econômicas, políticas e culturais é o ponto de partida para que se iniciem mobilizações e se implantem ações em prol de uma sociedade mais justa. Esse precisa ser um dos objetivos da escola, dado que é nesse ambiente que, talvez, pela primeira vez na vida, o sujeito se depara com a coletividade, com as diferenças e a multiplicidade de culturas. Isso é cada vez mais importante 
quando, do lado de fora da instituição educativa, sobram o individualismo, a competição, a busca incessante pelo capital e a intensificação das desigualdades. Num sistema marcado pela questão econômica impõe-se o individualismo, o conformismo e as exclusões sociais propagadas pelos discursos midiáticos e doutrinamentos ideológicos.

Como estratégia de combate, pensamos que o caminho seria percorrer uma política pedagógica de mudanças, assumindo a posição de sujeitos, de professores que lutam pela causa da transformação social. Dessa maneira, ressaltamos que diante de tantas contradições, a escola ganha espaço e importância na formação de identidades que compreendam esses emaranhados de relações e situações, posicionando-se diante delas de maneira crítica. É na escola que o educando pode pensar a respeito dele mesmo, dos outros e da sociedade. Nesse caso, as aulas passam a ser vistas como cenários vivos de interações em que se intercambiam explícita ou tacitamente ideias, valores e interesses diferentes e seguidamente conflitantes.

A questão que se coloca é se as escolas devem, de maneira acrítica, servir e reproduzir a sociedade, favorecendo poucos ou, de maneira crítica, transformar a ordem vigente e avançar nas lutas por democracia e equidade, favorecendo todos. Silva (2000) associa essa preocupação ao movimento do multiculturalismo e toma como base a "política de identidade" que enfatiza o processo social de produção da diferença e da identidade, em suas conexões, sobretudo, com relações de poder e autoridade. Nessa perspectiva, considera-se que a sociedade contemporânea é caracterizada por sua diversidade cultural, isto é, pela coexistência de diferentes e variadas formas étnicas, de gênero, religiosas etc., de manifestação da existência humana, as quais não podem ser hierarquizadas por nenhum critério absoluto ou essencial.

Daí surge a importância de se investigar a educação escolar de modo geral, bem como seus sujeitos, dentre eles, o professor. Sendo este último marcado por experiências, visões de mundo, posturas e discursos singulares dentro e fora do espaço escolar, em decorrência da sua função como agente da cultura, ele influencia sobremaneira a formação identitária dos seus alunos, bem como tem sua própria identidade influenciada por eles.

Muito embora os discursos circulantes de tom pessimista sinalizem para falta de alternativas, estudos recentes sugerem que um grupo de professores e professoras ${ }^{3}$ vem experimentando caminhos na tentativa de desenvolver uma proposta curricular sensível à diversidade e comprometida com a formação de identidades democráticas. Trata-se da perspectiva cultural da Educação Física, uma perspectiva de ensino em que, de maneira muito sintética, as diferenças culturais são reconhecidas mediante a tematização das práticas corporais produzidas e reproduzidas pelos vários grupos que coabitam a sociedade contemporânea. Pautada na teorização pós-crítica, tomam como referência a ocorrência das brincadeiras, danças, lutas, esportes e ginásticas para problematizar os discursos que as envolvem, bem como aos seus representantes, aprofundando e ampliando os conhecimentos dos estudantes (NEIRA, 2016a).

Longe de oferecer uma metodologia de ensino fechada, sequências didáticas ou etapas, a Educação Física cultural ou culturalmente orientada concebe a artistagem como uma forma de fazer educacional. O currículo é artistado por cada docente conforme o contexto em que se encontra e, principalmente, as respostas do alunado às atividades realizadas.

\footnotetext{
${ }^{3}$ Grupo de Pesquisas em Educação Física escolar da FEUSP. A produção em formato de relatos de experiência, vídeos, artigos, livros, capítulos de livro, teses e dissertações está disponível em: www.gpef.fe.usp.br
} 
Dado que, em termos teóricos, a proposta afirma reconhecer as diferenças (NEIRA, 2016b), surgiu o interesse de identificar quais elementos possam ter contribuído para a constituição de uma docência da Educação Física atenta à diversidade cultural. Em busca de respostas, foram entrevistados cinco docentes de Educação Física que atuam em duas redes públicas e afirmam colocar em ação a perspectiva cultural do componente. Após a transcrição das gravações, o material produzido foi submetido ao confronto com a teorização cultural.

\section{O ENFRENTAMENTO DA DIVERSIDADE CULTURAL}

A forma como os professores entrevistados enfrentam a diversidade cultural é pouco discutida no âmbito pedagógico e na própria sociedade contemporânea. Na maioria das vezes, o que se procura é simplesmente apagar as diferenças e fazer valer uma só cultura para todos. Além do mais, é uma questão que está presente no dia a dia da sociedade e precisa ser reconhecida. Não pode ser camuflada ou tratada como dificuldade ou anomalia.

O professor Fábio ${ }^{4}$ compreende a diversidade cultural como saberes de todos os grupos e sujeitos que transitam na sociedade. Sejam eles brancos, nordestinos, negros, homens e mulheres, sem distinção, e que possuem "diferentes formas de viver". O docente considera a diversidade um aspecto marcante, pois, quando entra nas salas de aula no início do ano letivo percebe o quanto isso é forte ao se deparar com várias culturas, várias histórias de vida, costumes, comportamentos, alunos novos provindos de outras realidades etc. Assim, quando mapeia o patrimônio do grupo e estabelece os objetivos pedagógicos, se preocupa em valorizar essa bagagem cultural. Compromete-se em construir um currículo culturalmente orientado possibilitando que a voz dos seus alunos seja ouvida e trazendo relações silenciadas e subjugadas. Relações estas, embasadas na política de identidade. Fábio reforça que "[...] não é possível fazer um trabalho sem valorizar esses saberes que estão presentes".

Apesar da escola reconhecer a configuração multicultural da sociedade contemporânea, o currículo, muitas vezes, é colocado em segundo plano. Fala-se muito em igualdade, mas o que ocorre no cotidiano escolar, na maioria das vezes, é a aplicação do discurso da igualdade como armadilha social, o que nos leva a buscar o desafio de uma escola igualitária pautada em novas pedagogias influenciadas pelo multiculturalismo, a fim de vermos contemplada a diversidade, valorizando, reconhecendo e fazendo dialogar as diferenças para que o outro presente em nossas escolas possa ser aceito e valorizado independente de seu credo, etnia, gênero ou classe social.

Hall (2005) define diferença como o conjunto de princípios que têm sido empregados nos discursos, nas práticas e nas políticas para categorizar e marginalizar grupos e indivíduos. O entrevistado foca justamente estes princípios para estabelecer relações com seus alunos e alunas, configurando práticas e discursos.

Quando a cultura dos alunos é valorizada e enaltecida, comenta o docente, tornase necessário entender os processos para socialização, significação, ampliação e ressignificação desses conhecimentos e saberes. Existem diversos caminhos a trilhar de forma igualitária, democrática e transformadora para evitar armadilhas teóricas e discursivas que busquem a homogeneização cultural. Pois, em alguns momentos podese camuflar relações de poder, preconceitos, negações, conduções e regulações nas estratégias para conduzir as ações didáticas na escola.

\footnotetext{
${ }^{4}$ Os nomes utilizados são fictícios.
} 
Pensando na Educação Física, isso acontece, segundo o professor Walter, quando as práticas corporais convencionais (futebol, basquete, vôlei e handebol) são abordadas de forma acrítica. Como alternativa, Canen (2000) defende que a educação questione a própria construção das diferenças e, por conseguinte, dos estereótipos e preconceitos contra aqueles percebidos como "diferentes" no âmbito das sociedades desiguais e excludentes.

$\mathrm{O}$ professor Walter menciona a grande diversidade cultural que cerca o meio social e escolar. Aponta que na escola em que trabalha o fenômeno é facilmente constatado através "[...] das pessoas que vêm de diferentes lugares, dos bairros próximos, de diferentes formações familiares" (WALTER). Consequentemente, surgem os conflitos de ideias. Pontua, ainda, que "[...] a diversidade é uma forma de diferentes culturas se manifestarem na sociedade" (WALTER) e exemplifica as distinções de significados que atribuem às coisas do mundo, por isso insiste na importância da escola propiciar espaços que garantam a liberdade de expressão dessa diversidade.

Ao narrar sua experiência enquanto aluno da Educação Básica, o entrevistado revela que há muito depara com a questão da diversidade cultural:

Ela (a Escola Estadual onde estudou) tinha espaço, a gente tinha [...] o festival do fim do século que era os talentos que a gente podia apresentar. Então você podia ali naquele espaço que de certa maneira era um espaço elitizado até pela questão do bairro, você tinha espaço para apresentar um pouco do que se fazia no outro lado da ponte (WALTER).

Observa-se a relevância atribuída ao momento da socialização das diferentes práticas, discursos e grupos. A percepção docente também recai sobre o sentimento de segregação por parte de grupos silenciados quanto ao espaço, já que a escola está situada em um bairro de classe média, mas uma parte considerável dos alunos reside em regiões com menor poder aquisitivo, ou seja, do "outro lado da ponte".

Vale o alerta para as relações que tinham lugar na escola e o processo de constituição das subjetividades. O espaço do festival de talentos se tornava um momento importante para os alunos subjugados mostrarem-se e resistirem à colonização. Um momento para o reconhecimento da diversidade de grupos e suas ideias, posturas, concepções etc. Na narrativa do entrevistado, existe um sentimento forte de não pertencer ao local, mas, ao mesmo tempo, lutar para pertencer. De não ser aceito, mas querer ser aceito. De enfrentar a situação de não reconhecimento e usar o festival para ser reconhecido. É perceptível como as relações de poder vão marcando os sujeitos e formandos suas identidades. Enfim, um momento para materializar as transformações.

$\mathrm{Na}$ visão de Moreira e Câmara (2010), a ênfase na identidade deriva do reconhecimento de que certos grupos sociais têm, há muito, sido alvo de inaceitáveis discriminações. Entre eles, incluem-se os negros, as mulheres e as pessoas que estabelecem relações homoafetivas. Tais grupos se rebelaram contra a situação de opressão que os têm vitimado e, por meio de árduas lutas, conquistaram espaços e afirmaram seus direitos à cidadania. Com muita tenacidade, têm contribuído para que se compreenda que as diferenças que os apartam dos "superiores", "normais", "inteligentes", "capazes", "fortes" ou "poderosos" são na verdade construções sociais e culturais que buscam legitimar e preservar privilégios. Além da afirmação das suas identidades, tais grupos sociais têm procurado desafiar a posição privilegiada das identidades hegemônicas.

Outra entrevistada entende que 
[...] a diversidade cultural tem relação com o que somos, como somos constituídos, como vivemos, como crescemos e como nos tornamos adultos. Essa diversidade cultural tem a ver com os nossos modos de convívio, tanto do convívio familiar dentro de certa sociedade, tanto quanto convívio social (VITÓRIA).

Percebe-se que, na opinião da docente, a bagagem cultural que todos os sujeitos trazem para a instituição escolar não pode ser deixada de lado, precisa ser contemplada tal como o exemplo do festival de talentos mencionado pelo professor Walter. Os alunos esperavam por aquela data. Era o momento de sair do silêncio e mostrar suas formas de ver o mundo.

Quanto à questão dos conhecimentos e saberes dos alunos, convém lembrar que as novas condições sociais também sugerem que os alunos estão pré-escolarmente socializados neste mundo, conformando uma base humana singular que não podemos ignorar, nem muito menos negar.

A professora Vitória é explícita: "Temos uma tendência a pensar que muitos de nós temos que ser iguais”. Eis um alerta para os riscos da homogeneização. Essa questão está ligada à sociedade contemporânea do consumo que conduz e regula o dia a dia dos sujeitos através da produção e circulação de bens, da massificação dos comportamentos, no discurso de se preparar para encarar um mercado de trabalho extremamente competitivo, no profissional que tem que se qualificar a todo o momento de forma desenfreada porque não pode ficar desatualizado. E assim as relações vão se consolidando.

Contudo, ao homogeneizar as ações no meio social, surgem formas mais fáceis de regulação, autorregulação, avaliação, consumo e produção dos grandes grupos que comandam as diretrizes políticas, econômicas e sociais das várias sociedades.

A escola também enfrenta a homogeneização do currículo por meio de qualificações, avaliações internas e externas, materiais didáticos etc. Porém, essa padronização com objetivos bem claros pode provocar resistências, transgressões e o não cumprimento, trazendo consigo os conflitos escolares.

De repente você deu uma aula, não deu certo... Então... Não dar certo é complicado! Você foi, teve problemas com a direção, com a coordenação, com o próprio sistema, não pode trabalhar determinada prática... Então, esses problemas a gente tem que enfrentar né. Temos problemas sim! (MARIA).

A entrevistada é bem específica:

Lá na escola eu tive um probleminha com o funk [...] que foi bilhete, uma mãe mandando bilhete; a gente respondia e chegava outro bilhete. Tivemos que fazer uma reunião extraordinária com as mães sobre esse trabalho. Oito mães apareceram, na sala eram dezessete crianças da Educação Infantil, e conversei com elas. Na verdade foi mais ouvir, porque nessa perspectiva eu tenho muito registro das crianças, com fotos, com vídeos e tal. Então, chamamos para reunião, ouvimos tudo que elas tinham para dizer e depois colocamos os vídeos das crianças falando a respeito do funk, o que elas achavam, as representações que elas tinham. Mas, é um modo de enfrentamento, não enfrentamento de combate de olha quem manda aqui sou eu, não é esse enfrentamento, mas essa coisa do diálogo, de atribuir significado ao que ela diz, de entender o que ela diz, tentar colocar o que a gente pensa enquanto escola, qual a função do que fazemos ali (MARIA).

Em uma escola que se aventura a reconhecer e trabalhar com a diversidade, os conflitos vão existir a todo o momento. O diálogo parece ser o meio encontrado pelos 
entrevistados para superar os obstáculos. "Então, nas minhas aulas eu procuro sempre ter esse diálogo pra ver as suas representações... As suas representações pra gente tentar desconstruir ou tentar colocar outras representações" (VITÓRIA).

Neira (2011) explica que no processo de possibilitar a voz dos representantes de outras culturas, o professor descobrirá o potencial das linguagens corporal, oral, digital, musical, pictórica, entre outras, comumente mais acessíveis às crianças e jovens, além das linguagens já dominadas em seu cotidiano. No diálogo cultural, o professor terá que trabalhar dialeticamente entre a ideologia da cultura dominante europeia $\mathrm{e}$ estadunidense e as ideologias das culturas migrantes, infantis, familiares, juvenis, trabalhadoras, tecnos, afros, emos, rockeiras etc. As manifestações culturais não mais serão apresentadas do ponto de vista exclusivo do colonizador branco, macho e patriarcal, ou do capital, mas sim, serão incorporados, como conteúdos de ensino, ou seja, equiparam-se os pontos de vista do colonizado, escravizado e explorado aos dos grupos dominantes.

Observa-se que as ações didáticas baseadas no diálogo e no ouvir se tornam aliadas cruciais no processo formativo.

Eu acredito que o panorama da diversidade cultural tem que estar ligado à escola. E não só à escola, à minha prática de ensino também, por isso que eu me preocupo. É... Eu sempre procuro contemplar... As diversas culturas que estão ali. Que tão inseridas nas aulas. Eu fico muito preocupado porque no cenário social hoje acho que a diversidade cultural ela é evidente, então uma vez que é evidente na sociedade, a escola não tem que só reproduzir (FÁBIO).

O docente também alude às relações étnicas no meio escolar:

Eu fico pensando nessas questões, no ensino fundamental eu estudei numa escola de classe média baixa então era um dos poucos negros que ali estavam. E eu sofria com essa condição. Eu acho que esse foi um dos fatores pra eu ficar atento à diversidade cultural. Acredito também que a questão racial ela tenha pegado, em alguns momentos da minha vida fora da escola também (FÁBIO).

$\mathrm{Na}$ narrativa percebemos o preconceito que o docente sofreu por pertencer a um grupo minoritário, o que produz a segregação por meio de discursos, práticas e representações. Isto pode ter desencadeado uma postura pedagógica contrária a ações de discriminação, preocupando-se em como essas relações são estabelecidas e os caminhos para serem questionadas no espaço escolar. As questões étnicas também estão na escola e precisam ser discutidas.

Da mesma forma, a professora Maria ressalta que vivemos numa sociedade multicultural e devemos tratar "a cultura como centro da vida das pessoas" enfatizando as variadas formas de entender o mundo. A diversidade, para ela, "[...] é quando você reconhece e traz pra dialogar as diversas formas de cultura" (MARIA). Ressalta que os docentes devem promover o diálogo, como enfatizaram seus colegas, para conhecer melhor, aprofundar e ampliar o entendimento das diversas culturas.

O professor João Francisco traz outro olhar sobre o tema:

Vamos aceitar a diversidade cultural, mas no sentido de acomodação, de aceitar mesmo e não de compreender aquilo. Como algo que representa a identidade de certos grupos. Ah, ele se manifesta culturalmente diferente de mim. Ah, diversidade! Vamos aceitá-lo e não compreender o porquê disso, o porquê o sujeito se expressa de outro modo. Então acho que diversidade 
precisa ser repensada quanto às questões afirmativas! Entendeu? Acho que traz uma ideia de tolerância.

A crítica do entrevistado deve-se ao fato de que tolerar pode ter a conotação de conviver com o diferente, desde que cada qual permaneça no seu espaço e não tenha interação com os demais. Para Perez Gómez (2001), a escola deve ser concebida como um espaço ecológico de cruzamento de culturas, cuja responsabilidade específica que a distingue de outras instâncias de socialização e lhe confere identidade e relativa autonomia, é a mediação reflexiva daquelas influências plurais que as diferentes culturas exercem de forma permanente sobre as novas gerações.

Em contrapartida, não se pode pensar que tudo diz respeito à diversidade cultural. Como o docente colocou: "Manter tudo sobre um mesmo manto, seria um meio de apagar as diferenças, vamos pôr tudo aqui, tudo da diversidade e a gente aceita, não precisa pensar nisso" (JOÃO FRANCISCO).

$\mathrm{Na}$ opinião do entrevistado, os temas referentes ao multiculturalismo, diversidade cultural, diferença e identidade são interpretados de diversas formas e até mesmo confundidos pelos sujeitos da educação. Segundo Kincheloe e Steinberg (2012), o multiculturalismo costuma referir-se às intensas mudanças demográficas e culturais que têm conturbado as sociedades contemporâneas. Por conta da complexa diversidade cultural que marca o mundo de hoje, há efeitos (positivos e negativos), que se evidenciam em todos os espaços sociais, decorrentes de diferenças relativas à etnia, gênero, sexualidade, cultura, religião, classe social, geração, deficiências ou outras dinâmicas sociais.

A presença da diferença obriga a reconhecer a diversidade cultural, forma parte de um programa defendido pela perspectiva democrática, é uma pretensão das políticas de inclusão social e se opõe ao domínio das totalidades únicas do pensamento moderno. Contrapondo o pensamento moderno, o projeto pós-moderno propõe uma perspectiva educacional que resista às tendências homogeneizadoras provocadas pelas instituições fundadas na modernidade, inclinadas ao universalismo. A intenção é dissipar as forças que levam a categorizar, normatizar e classificar de alguma forma os processos pedagógicos e os seus sujeitos.

Manter essa complexidade sob um "mesmo manto", como aponta o professor João Francisco, pode camuflar uma série de relações que negam o outro. Pode apenas tolerar a diversidade sem entender a naturalização de ações preconceituosas, a homogeneização e padronização dos processos pedagógicos, a formatação de condutas e comportamentos, o diagnosticar ações e reações dos discentes para domesticá-los etc.

João Francisco reforça a dificuldade de entender esses termos culturais, o que acaba causando transtornos pela má interpretação e ação no meio escolar e social:

Essa diversidade no sentido assim: existe a sua cultura que ela partiu daqui que é híbrida, que não é, que não é cristalizada, mas, ela é assim por isso e por isso, a sua é assim pela sua origem, das coisas que você acessa ao longo da vida. Mas não como diversidade em si, eu acho que diversidade apaga uma série de coisas, hoje estou pensando assim, eu acho que ela apaga umas coisas aí.

O enfrentamento das dificuldades causadas pela diversidade parece ter permeado a vida de alguns entrevistados. O professor Walter é o mais novo de três irmãos e seus pais trabalhavam muito, por isso foi criado pela avó. Durante a semana ficava na casa dela e, nos finais de semana, na casa da sua mãe. Dessa maneira, acessava dois locais diferentes com variadas representações: 
De segunda a sexta eu ficava na casa da minha avó e de sábado e domingo eu ficava na casa da minha mãe [...], na casa da minha avó por condição ser um pouco melhor eu acessava um determinado grupo, então, por exemplo, tinha duas escolas próximas da casa da minha avó eu, eu estudava naquela escola do Estado que era caracterizada como a escola dos "playboys", das pessoas ricas enquanto que da Prefeitura era das pessoas menos favorecidas [...] Agora olhando percebo que as pessoas faziam força para que aquelas determinadas crianças fossem para lá e nós fôssemos para outra escola porque a gente morava no bairro onde tinha casa e tal. No final de semana, meus pais moravam mais na periferia. No final de semana ia para casa dos meus pais e era interessante porque, se durante segunda à sexta os amigos eram os ricos, eu era considerado o mais pobre. Se, em um determinado momento eu vivia num grupo onde eles ridicularizavam os negros, no outro momento eu vivia com eles e conseguia entender quem eram eles, e para mim esses negros não eram essas pessoas que os meus amigos falavam que eram. E aí, o interessante é que naquela mesma rua tinha um garoto que depois de anos eu vim saber que ele era homossexual e ele foi meu amigão porque ele era mais velho, então ele tinha, eu devia ter uns 10, 11 anos e ele uns 20, ele sofria muito preconceito dentro da escola, da rua porque ele não trabalhava, mas fazia os afazeres de casa e como era muito novo eu não estava nem aí para esse cara, e ele era meu amigo.

$\mathrm{Na}$ fala do educador percebe-se o emaranhado de relações que vivenciou. Transitando no bairro dos ricos com predominância de pessoas brancas e no outro, mais pobre, convivia com pessoas negras. Construiu, assim, suas representações e significados. Descentrando suas várias identidades e percebendo o quanto era hostilizado em determinado local e aceito em outro. Diante das experiências na infância, de enfrentamento da diversidade cultural, passou a questioná-las.

Essas trajetórias de discriminação, essas trajetórias de não entender o outro, não sei o quê, isso aí, marcou muito a minha vida, entendeu? Acho que faz com que eu tenha o olhar diferente, um outro tipo de olhar para diversidade. Então, toda vez que eu lanço um olhar sobre aquela cultura eu reflito sobre o que eu estou dizendo para eles e procuro muitas vezes tentar acessar aquelas pessoas para tentar entender quem são elas, não ficar olhando para elas com o meu olhar, por conta de toda essa trajetória de vida né (WALTER).

A experiência pessoal de contato com a diversidade também foi mencionada pelo professor Fábio:

[...] eu acredito que toda a minha história de vida, toda a minha formação não só enquanto professor de Educação Física mas, em quanto homem, pai, enfim acredito que isso já era uma preocupação anterior na minha vida é... Porque... Por vir de favela né é... Chegar em vários espaços. Nossa, você mora na Brasilândia! Nossa você mora no... Você chegar nos lugares e o pessoal falar: Nossa você..., pô lá pra mim é legal cara né, não é uma coisa. Nossa, mas você viu o que aconteceu na Brasilândia! Nossa, mataram não sei quem na Brasilândia! Então, por vir de um lugar assim e você chegar nos espaços e ver que os outros lugares são diferentes e tudo bem desses espaços serem diferentes. E aí você começa, no meu caso, a partir da capoeira eu... Fui fazer Educação Física. Você chegar e ver que naquele espaço o que você pratica não é reconhecido e num determinado momento você descobre que existiria no terceiro ano da faculdade lá uma disciplina que cuidava dessas questões.

O entrevistado credita à escola a possibilidade de transformação desse contexto.

A escola é um espaço de transformação! E... Eu acredito que assim, a decisão depois né, de ser professor de Educação Física. Da capoeira, de já dar aula. 
Eu acho que veio nessa... Nessa ideia de que poxa eu posso fazer alguma coisa mesmo que não seja num né, num nível macro seja micro, mas alguém tem que fazer alguma coisa; acho que um pouquinho dá pra contribuir. Não que vá mudar o mundo, mas que alguma coisa você pode contribuir e trabalhando em escola pública você acaba se sentindo responsável! Por... Uma, mesmo que pequena mudança. Que afinal as pessoas elas pagam os impostos! Têm a vida delas, a dificuldade do dia a dia e você tá lidando com dinheiro público e com coisa pública e acredito que a gente tem que ter uma seriedade muito maior (FÁBIO).

Ficou latente que a trajetória do professor Fábio assemelha-se à dos demais. As experiências acumuladas foram decisivas para perceber o quanto é importante entender a construção de relações injustas e poder desconstruí-las num ambiente como a escola:

\begin{abstract}
Por isso eu acho que às vezes o professor que vem de outra história talvez possa ter uma sensibilidade maior na questão da injustiça, da marginalidade. Assim "marginalizado", o aluno marginalizado. A gente vê na escola muitas práticas de exclusão no meu entender, a questão do envelopinho da APM. A criança sabe que o dela foi sempre "vaziozinho" e o outro sempre tinha uma moedinha ou uma notinha, então como que ela se sente. [...] os passeios que são pagos e um monte não pode ir [...] E aí é muito complicado explicar o porquê disso numa perspectiva teórica porque você dá conta de explicar [...] isso é exclusão [...] e o outro diz "não, dez reais todo mundo tem! Não, cinco reais todo mundo tem" [...] Que eu fui, da criança lá que não ia nos passeios. Eu me vejo a criança que o envelopinho ia vazio [...] acho que fica muito mais fácil talvez de ter uma sensibilidade, de olhar esse outro e tentar dar voz, tentar promover a justiça, tentar brigar mais por essas coisas, talvez seja isso assim. Porque acho que só a teoria não move tanto (FÁBIO).
\end{abstract}

Por meio dessa narrativa, percebemos que a cultura escolar não poderá, em seus discursos e práticas, fazer com que os representantes das minorias sintam-se acolhidos se escola não tratar adequadamente o tema e discutir a diversidade cultural.

Tendo em vista a possibilidade de colaborar na desconstrução de relações de poder envolvidas nos discursos e práticas estabelecidas pela sociedade contemporânea, a análise da transcrição das entrevistas fez transparecer o modo como organizam e desenvolvem as aulas. Não se limitam a determinadas práticas corporais nem tampouco à transmissão de dados históricos e reprodução da gestualidade específica. Os conteúdos de ensino da Educação Física se estendem para muito além daquilo que se tem sido contemplado nos currículos convencionais, aqueles que, segundo Neira (2016a), se abstêm de analisar os significados políticos e sociais das práticas corporais ao longo do tempo.

$\mathrm{Na}$ visão do professor João Francisco, "existem docentes que reproduzem práticas, ações e situações didáticas sem entender os verdadeiros objetivos por questões de comodidade ou simplesmente porque não acessaram outros conhecimentos". Nesses casos, o próprio desencadear das relações pedagógicas entra num emaranhado de situações que inviabilizam o desvelar dos caminhos da construção daquelas práticas educacionais. Os docentes são levados a reproduzir práticas pedagógicas pensando que estão trazendo avanços à comunidade escolar. Essa reprodução é uma das formas de perpetuar certos objetivos no espaço escolar sejam eles, de mercado, de produção, políticos etc. É uma maneira de homogeneizar os currículos, as ações didáticas, os sujeitos e as identidades.

Silva (2000) concebe a reprodução social como processo pelo qual são perpetuadas, ao longo do tempo, as relações de dominação entre os vários grupos sociais. Na teorização marxista, essas relações se dão entre classes sociais, definidas por sua situação relativamente à propriedade dos meios de produção. O conceito é central na 
teoria educacional crítica porque se argumenta que a educação tem um importante papel no processo de reprodução social. É sobretudo através da reprodução das posições das diferentes classes sociais frente à cultura dominante isto é, do processo de reprodução cultural, que a educação contribui para o processo de reprodução social.

Muito embora a perspectiva pós-crítica agregue as noções da teoria crítica, não se restringe a elas. Uma Educação Física cultural amplia o leque de análises e questionamentos a respeito da rede social e política. Estabelece a escolarização como uma forma de política cultural e não de simples reprodução ou homogeneização da cultura dominante. Nessa perspectiva, o currículo inclui novas temáticas e categorias para compreender as relações entre poder e identidade social no espaço escolar: a etnia, o gênero, a religião etc.

Candau (2008) considera relevante proporcionar espaços em que os alunos percebam a construção da própria identidade cultural, relacionando-a com a história de seu país e os processos socioculturais que a constituíram e a constituem. Recomenda que a escola promova o entendimento dos enraizamentos culturais, dos processos de negação e silenciamento de determinados pertencimentos, a fim de que os estudantes possam reconhecê-los e trabalhar com eles.

A professora Maria visualiza mudanças na área:

\begin{abstract}
Eu vejo que certos avanços em relação às teorias [...] Elas estão procurando responder à demanda da sociedade né. Outras teorias procuram responder a certa demanda que eu acho que não responde à sociedade atual, mas responde à sociedade em outro momento histórico, porém essas teorias que querem responder à sociedade a esse momento histórico elas ainda, elas permanecem porque não é uma coisa estanque né, acaba uma teoria entra outra, acaba uma teoria são várias visões de mundo e interpretações que os teóricos, não só os teóricos, as pessoas que estão nas unidades escolares têm sobre a área de Educação Física.
\end{abstract}

Quando se discute sobre as demandas da sociedade é preciso entender quais são. Se estão vinculadas às questões sociais (moradia, educação, saúde) ou ancoradas na economia e direcionadas ao consumo. As questões sociais estão ligadas à formação de sujeitos críticos, democráticos e transformadores das relações sociais. Tendo uma formação voltada não só para o trabalho, mas para ajudar na constituição de uma sociedade justa que abarque todos, sem discriminação e com oportunidades. Em contrapartida, há interesses na formação dos sujeitos voltados exclusivamente às questões de mercado. Determinados setores concebem a escola como um local para formação de cidadãos produtores e consumidores pensando apenas nas situações materiais, no capital e nas formas de gerir melhor os dividendos. Desta maneira, estabelece-se uma formação direcionada ao desenvolvimento de técnicas para aumentar a produção sem se preocupar com as relações dos seus sujeitos e como interagem na sociedade. Aliado a isso, há também quem pense em ampliar o montante de sujeitos consumidores dos produtos.

A professora Maria ressalta, ainda, a existência de posturas e discursos cristalizados:

A Educação Física também é cristalizada de algumas práticas né. Uma vez que a educação está muito ligada àquilo que vivemos, então as pessoas tendem a olhar, algumas pessoas tendem a olhar esse processo como a Educação Física que tiveram lá na educação básica como boa.

No entendimento da entrevistada, essa visão saudosista não dialoga com os alunos que hoje estão na escola: “[...] é desses alunos que estão antenados com certo mundo 
tecnológico, mundo onde a dinâmica é muito rápida, onde as informações não são aprofundadas, são superficiais" (MARIA). Todavia, completa: "Eu vejo mudanças em relação à maneira de ver o processo educacional do componente curricular Educação Física. É essa nova ótica. Várias áreas do conhecimento vêm permear a Educação Física e isso está contribuindo" (MARIA).

A professora manifesta uma concepção de Educação Física culturalmente orientada. Em termos didáticos, tem como ponto de partida o mapeamento da realidade em questão assim exemplificada:

Eu o elaboro de diversas maneiras. Uma última experiência de prática eu fiz mapeamento com desenho e aí as crianças no terceiro ano, elas falaram o que eles desenharam para eu detectar alguns elementos que estão ali referentes à cultura corporal de movimentos desses alunos (MARIA).

Por essa razão, Neira e Nunes (2009) reforçam que é importante que as manifestações culturais estudadas se relacionem aos grupos de origem e ao pertencimento cultural dos estudantes. Tal situação se estende para os saberes e preferências dos alunos e das alunas quanto às manifestações abordadas nas aulas, pois, muitas vezes, eles são apreciadores "à distância", o que também se caracteriza como aspecto identitário.

Todavia, o professor Walter destaca a dificuldade em alguns momentos de trabalhar de maneira culturalmente orientada: "Em algumas turmas, o projeto vai sendo construído e em outras acontecem resistências, embates e desconfortos de ambos os lados".

Acertadamente, o entrevistado busca apoio no diálogo e no trabalho coletivo.

\begin{abstract}
A minha aflição, às vezes, é ter que dar conta de tudo e não conseguir. Tentar dar conta de tudo e não dar conta de nada. Então eu acho que fica a minha aflição nisso. Mas eu tenho lá na escola um grupo de professores de Educação Física que eu trabalho, que a gente conversa muito, a gente conversa todo dia sobre as aulas, sobre outras coisas, mas sobre as aulas, sobre as nossas práticas. E aí, a gente fica repensando, mas pera aí, se não deu pra atingir isso aqui agora em outro momento com a mesma turma, mas em outra manifestação corporal, enfim, eu acho que dá, se surgir de novo, se emana do grupo dá pra fazer essas discussões (WALTER).
\end{abstract}

$\mathrm{Na}$ fala do docente, a noção de "dar conta de tudo" precisa ser repensada porque, enquanto educadores, não daremos conta de ensinar, explicar, mudar visões de mundo de todos, mudar radicalmente certos discursos. Até porque as pessoas pensam e agem diferentemente. Traçaremos sim, caminhos de novas construções e desconstruções sem pretender um efeito imediato; mostraremos as realidades como foram construídas e como estão atualmente; inseriremos novos textos no dia a dia dos discentes; e abriremos espaços para discussões. Mesmo assim, estaremos distantes da ideia que eles aprenderão todos os saberes e conhecimentos no espaço escolar. Precisamos entender que a formação de identidades, tanto dos alunos quanto dos professores, se faz através de um processo longo, continuo e transitório.

O objetivo da perspectiva cultural da Educação Física é possibilitar a leitura e a reconstrução crítica das práticas corporais, estabelecendo relações entre a cultura corporal e a cultura mais ampla, tencionando sua análise e ações em prol da ampliação das representações acerca das práticas corporais e dos seus representantes.

Os diversos discursos que pairam na escola estremecem, consolidam e potencializam as práticas pedagógicas e seus sujeitos. Por essa razão, Neira (2011) assevera a urgência de conferir mais seriedade e fundamentação ao que se diz e ao que 
se ensina. Frases de efeito ou aforismos desprovidos de criticidade e rigor devem ser varridos do currículo ou, minimamente, colocados sob análise. O mesmo deve ser feito com as práticas pedagógicas. Os professores têm a obrigação de submeter suas próprias posições à análise dos alunos. Ora, todos têm o direito de saber que existem posicionamentos divergentes sobre todos os assuntos tratados no currículo.

\section{CONSIDERAÇÕES FINAIS}

A análise da transcrição das entrevistas mediante o confronto com o arcabouço da teorização cultural permite suspeitar que os elementos que contribuíram para a constituição de uma docência da Educação Física atenta à diversidade possuem alguma relação com a trajetória de vida desses professores, sobretudo o enfrentamento de situações em que ocuparam o lugar da diferença, ocasião em que foram vítimas de preconceitos, e suas experiências com práticas corporais contra-hegemônicas.

$\mathrm{O}$ fato de terem atravessado momentos marcantes pode ter influenciado suas ações atuais como docentes e o questionamento das suas construções. Alguns exemplos são os episódios narrados pelos professores com relações de silenciamento, negação, preconceito e regulação: "a capoeira como uma prática de malandro", "o envelopinho destinado para alguns alunos", "a vivência em bairros ditos de ricos e os de pobres", "a convivência com sujeitos negros" etc.

Tais passagens podem ter desencadeado nos narradores uma postura reflexiva e de ruptura de padrões sociais no que respeita às relações naturalizadas. Logo, a tentativa de não silenciar como em alguns momentos foram silenciados, entendendo e demonstrando para os alunos e alunas que o mundo é cercado por relações de poder disseminadas pela sociedade e presentes também no espaço escolar. Um ponto importante, alertam os dados analisados, é reconhecer o outro, independente das suas fragilidades e situação social. Os docentes destacam a importância de ouvir os múltiplos sujeitos do processo educacional, enaltecendo a construção do currículo a partir dessas pessoas, valorizando suas ideias e suas visões de mundo.

As análises indicam o quanto os entrevistados estão comprometidos com o desenvolvimento do currículo cultural da Educação Física independentemente das dificuldades que se apresentam, comungam da ideologia das teorias pós-críticas quando afirmam que a educação necessita entender e respeitar a diversidade cultural.

A pesquisa realizada reforça a ideia que mediante o estudo contextualizado das práticas corporais na Educação Física é possível adquirir uma visão mais ampla que os interesses particulares de determinados grupos sociais, proporcionando um novo olhar para o componente e consequentemente para a educação.

Ao tematizar as práticas corporais contra-hegemônicas fazendo-se acompanhados das histórias de luta que os seus representantes empreenderam por reconhecimento e dignidade, serão criadas condições para ver, ouvir e, enfim, compreender o outro.

Os resultados do estudo chamam a atenção para a adoção de algumas posturas didáticas:

a) Questionar os modelos educacionais prontos que não levam em consideração as diversas realidades e os sujeitos com suas bagagens culturais, experiências de vidas, visões de mundo e formas distintas de relacionar-se;

b) A relevância de socializar os conhecimentos referentes à cultura corporal de todos os alunos;

c) A importância do encontro com outros discentes para estabelecer os caminhos educacionais a serem traçados; 
d) A utilização dos espaços coletivos como momentos fundamentais do processo democrático;

e) Questionar os discursos estranhos à prática e à função da escola, deixando bem claro que a proposta objetiva formar sujeitos críticos, participativos e que transformem as relações sociais em prol da equidade, democracia e o convívio entre todos;

f) Indagar constantemente as relações que insistem em permanecer ocultas no ambiente escolar.

O presente estudo foi de suma importância para refletirmos sobre a maquinaria que se faz presente na sociedade contemporânea influenciando a educação e, consequentemente, a Educação Física. Por meio das teorias, autores e pesquisas recentes de educadores que se preocupam em experimentar alternativas para uma educação de qualidade, democrática, igualitária e justa para todos, questionamos não só os discursos e práticas dos diversos sujeitos, mas também, as nossas próprias práticas no território escolar. Assim, este trabalho, estremeceu as concepções que tínhamos acerca da docência, desestabilizou nossas ações didáticas e abriu espaço para novos olhares a respeito da lida com a diversidade cultural na escola. A partir dele acreditamos ainda mais na relevância de estudos com essa natureza e apontamos como necessária sua continuidade em futuras pesquisas.

\section{REFERÊNCIAS}

CANDAU, V. M. Direitos humanos, educação e interculturalidade: as tensões entre igualdade e diferença. Revista Brasileira de Educação, v. 13, n. 37, p. 45-56, jan./abr. 2008.

CANEN, A. Educação multicultural, identidade nacional e pluralidade cultural: tensões e implicações curriculares. Cadernos de Pesquisa, n. 111, p. 135-149, 2000.

HALL, S. A identidade cultural na pós-modernidade. Rio de Janeiro: DP\&A, 2005.

KINCHELOE, J. L.; STEINBERG, S. R. Repensar el multiculturalismo. Barcelona: Octaedro, 2012.

MOREIRA, A. F. B.; CÂMARA, M. J. Reflexões sobre currículo e identidade: implicações para a prática pedagógica. In: MOREIRA, A. F. B.; CANDAU, V. M. (Orgs.). Multiculturalismo: diferenças culturais e práticas pedagógicas. Petrópolis: Vozes, 2010. P. 38-66.

NEIRA, M. G. Educação física cultural. São Paulo: Blucher, 2016a.

NEIRA, M. G. Educação Física cultural: carta de navegação. Arquivos em Movimento, v. 12, n. 02, p. 82-103, jul.-dez. 2016b.

NEIRA, M. G. Educação física. São Paulo: Blucher, 2011.

NEIRA, M. G.; NUNES, M. L. F. Educação Física, currículo e cultura. São Paulo: Phorte, 2009.

PÉREZ GÓMEZ, A. A cultura escolar na sociedade neoliberal. Porto Alegre: Artmed, 2001.

SILVA, T. T. Teoria cultural e educação - um vocabulário crítico. Belo Horizonte: Autêntica, 2000.

Recebido em: 12 out. 2017.

Aprovado em: 26 out. 2017. 